\title{
Seismological Aspects of the Guatemala Earthquake of February 4, 1976
}

\author{
Hiroo Kanamori and Gordon S. Stewart \\ Seismological Laboratory. California Institute of Technology, Pasadena, California 91125
}

\begin{abstract}
Detailed analyses of teleseismic surface waves and body waves from the Guatemala earthquake of February 4, 1976, show the following: (1) Left lateral displacement along a vertical fault with a strike varying from $\mathrm{N} 66^{\circ} \mathrm{E}$ to $\mathrm{N} 98^{\circ} \mathrm{E}$ is consistent with the teleseismic data. (2) The seismic moment was $2.6 \times$ $10^{27}$ dyn $\mathrm{cm}$. The directivity of the surface wave radiation indicates an asymmetric $(1: 23)$ bilateral faulting with a total length of $250 \mathrm{~km}$. In modeling the displacement a rupture velocily of $3 \mathrm{~km} / \mathrm{s}$ was used, and the fault curvature was included. (3) If a fault width of $15 \mathrm{~km}$ is assumed, the average offset is estimated to be about $2 \mathrm{~m}$. This value is about twice as large as the average surface offset. (4) Although the observed directivity suggests a uniform overall displacement along the fault, the body wave analysis suggests that the earthquake consists of as many as 10 independent events, each having a seismic moment of $1.3-5.3 \times 10^{20} \mathrm{dyn} \mathrm{cm}$ and a fault length of about $10 \mathrm{~km}$. The spatial separation of these events varies from 14 to $40 \mathrm{~km}$. This multiple-shock sequence suggests that the rupture propagation is jagged and partially incoherent with an average velocity of $2 \mathrm{~km} / \mathrm{s}$. (5) The average stress drop estimated from surface waves is about 30 bars, but the local stress drop for the individual events may be significantly higher than this. (6) The complex multiple event is a manifestation of a heterogeneous distribution of the mechanical properties along the fault, which may be caused by either asperities, differences in strength. differences in pore pressure, differences in slip characteristics (stable sliding versus stick slip), or combinations of these factors. (7) This complexity has important bearing on the state of stress along transform faults and is important in assessing the effect of large earthquakes along other transform faults like the San Andreas.
\end{abstract}

\section{INTRODUCTION}

The Guatemala earthquake of February 4, 1976 (0901:42.2 $\mathrm{UT} ; 15.27^{\circ} \mathrm{N}, 89.25^{\circ} \mathrm{W} ; M_{s}=7.5 ; m_{b}=5.8$ ), not only is one of the most disastrous earthquakes in recent history but also is unique in various aspects. According to the preliminary reports of the U.S. Geological Survey [Espinosa, 1976] and Plafker [1976], this earthquake is one of the largest events of transform fault mechanism, characterized by a very long fault with a relatively shallow depth. The surface breaks associated with this earthquake have been mapped in detail by Plafker et al. [1976], and the distribution of aftershocks has been studied by Person et al. [1976], Langer et al. [1976], and Matumoto and Latham [1976]. Teleseismic data are very complete and have been used to study the fault mechanism of this earthquake [Dewey and Julian, 1976; Kanamori and Stewart, 1976b]. This completeness of various kinds of data warrants a further seismological investigation into the details of the faulting mechanism of this important event. This paper is primarily concerned with (1) a comparison of the surface offset with the displacement determined from seismological data, (2) the variation of the displacement along the fault, and (3) the complexity of the rupture propagation along the fault. These features will provide a key to the understanding of the nature of plate motion along transform faults, as well as the mechanical properties of earthquake faulting. The results will be useful for predicting the nature of faulting in other major transform fault earthquakes, such as the 1906 San Francisco and the 1857 Fort Tejon type earthquakes along the San Andreas fault.

In this study, long-period surface waves were used to constrain the overall source parameters such as the seismic moment and the directivity, and body waves were used to study the details of the faulting. The far-field body waves recorded on the World-Wide Standard Seismograph Network (WWSSN) long-period seismograms are very complex, an indication that the Guatemala earthquake is a multiple event. It is widely known that most large earthquakes are multiple

This paper is not subject to U.S. copyright. Published in 1978 by the American Geophysical Union.

Paper number 8B0225. shocks. Imamura [1937, p. 267] made a detailed analysis of seismograms of the 1923 Kanto earthquake to determine the location and the size of the individual events of the multipleshock sequence. Wyss and Brune [1967] analyzed a large number of seismograms of the 1964 Alaskan earthquake and located six individual events. From the time intervals between these events they obtained an average rupture velocity of 3.5 $\mathrm{km} / \mathrm{s}$. Other studies pertinent to multiple shocks include those of Miyamura et al. [1964] and Trifunac and Brune [1970]. These studies clarified the details of complex rupture propagation associated with very large earthquakes. In the present study we match the observed $P$ wave forms with synthetic wave forms to investigate the details of the rupture propagation associated with the Guatemala earthquake.

\section{Basic Seismological Data}

The $P$ wave first-motion data are shown in Figure 1 and are listed in Appendix Table A $1 .{ }^{1}$ All of the data points were read by the authors from the WWSSN records. The result is consistent with that given by Dewey and Julian [1976]. The dip angles and the strike directions are shown in the figure. The strike of the northeast trending nodal plane and the sense of displacement along it agree with those of the Motagua fault at the earthquake epicenter.

The distribution of aftershocks shown in Figure 1 is taken from Langer et al. [1976]. The horizontal and vertical extent of the aftershock zone and the location of the main shock with respect to the aftershock zone were used to constrain partially the geometry of the fault plane.

Figure 2 shows surface waves $G_{3}$ (Love waves) and $R_{3}$ (Rayleigh waves) which were recorded by the WWSSN long-period seismographs and equalized to a propagation distance of $360^{\circ}$ $+90^{\circ}$. The method of equalization is that described by Kana-

\footnotetext{
${ }^{1}$ Appendix Table $\mathrm{Al}$ is available with entire article on microfiche. Order from American Geophysical Union, 1909 K Street, N. W., Washington, D. C. 20006. Document J78-004; \$1.00. Payment must
} accompany order. 


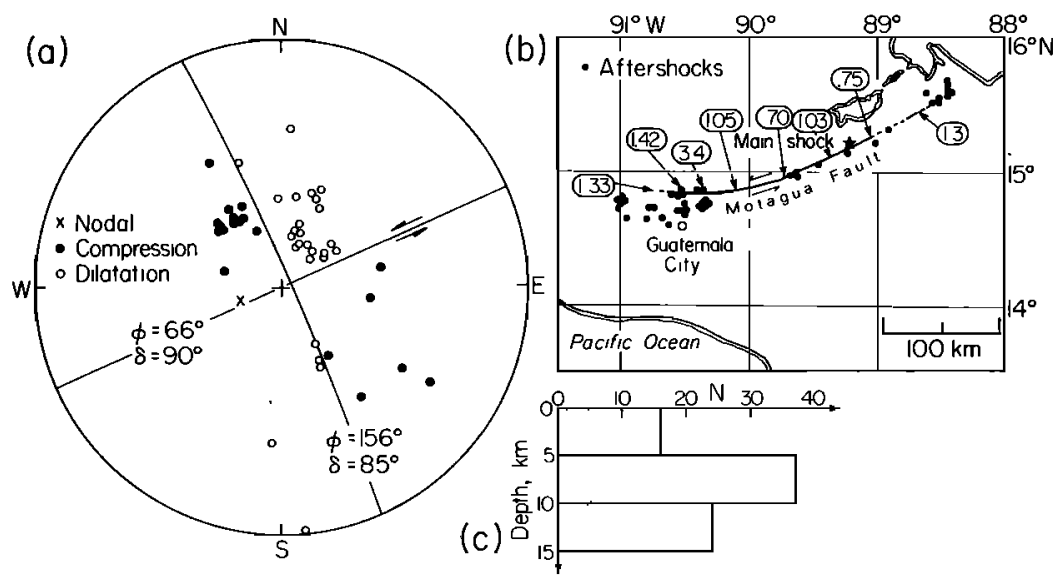

Fig. I. (a) The $P$ wave first-motion data for the Guatemala earthquake, indicating left lateral strike slip motion on the preferred fault striking $\mathrm{N} 66^{\circ} \mathrm{E}$. A stereographic projection of the lower focal hemisphere is shown. (b) A map of the main shock and aftershock locations. The abserved displacements along the Motagua fault are plotted inside the circles (values are in meters) [after Langer et al., 1976; Plafker, 1976]. (c) A plot of the number of aftershocks as a function of depth [after Langer et al., 1976].

mori [1970]. Short-period surface waves have been removed by using a filter described by Kanamori and Stewart [1976a] with a short-period cutoff at $40 \mathrm{~s}$. Both Love and Rayleigh waves indicate a four-lobed radiation pattern which is consistent with the fault geometry determined by the $P$ wave data shown in Figure 1. The theoretical radiation patterns of Love and Rayleigh waves for a shallow strike slip fault are shown by Kanamori and Stewart [1976a]. These are the fundamental seismological data sets to be used in the following analysis.

\section{Surface Wave Analysis}

Since short-period ( $T \leq 40$ s) surface waves are severely affected during propagation by structural heterogeneities, only long-period signals were used in the present analysis to determine the seismic moment $M_{0}$.

As is shown in Figure 2, since the overall radiation pattern is consistent with the geometry determined from $P$ waves, we first computed synthetic surface waves for a point doublecouple source corresponding to the $P$ wave mechanism. The point source had the same epicenter as the main shock and a depth of $16 \mathrm{~km}$. The method of synthesis, the velocity, and the $Q$ structure are described by Kanamori [1970] and Kanamori and Cipar [1974]. The same filter as was used for the observed records was applied to the synthetic records so that they could be compared directly. The maximum trace amplitudes of the observed and synthetic records are compared in Figure 3 as functions of azimuth. Although the overall agreement is satisfactory, the observed amplitudes are clearly too small in the azimuthal range of $0^{\circ}-90^{\circ}$, indicating a rupture propagation toward the west. This direction of propagation is consistent with the location of the main shock relative to the aftershock zone. A seismic moment of $2 \times 10^{27} \mathrm{dyn} \mathrm{cm}$ gives a reasonably good fit. The preliminary analysis made by Dewey and Julian [1976] using a point source and estimated spectral amplitudes of $G$ waves at 100 -s period gave a value, $2.6 \times 10^{27}$ dyn $\mathrm{cm}$, which is in reasonably good agreement with this value, despite their simplified method.

The slight asymmetry of the observed radiation pattern can be explained in terms of the directivity [Ben-Menahem, 1961]. To a first approximation the fault geometry shown in Figure 1 can be modeled by an asymmetric bilateral fault with $\delta=90^{\circ}$, $\phi=75^{\circ}$, and $\lambda=5^{\circ}$ extending over a distance of $250 \mathrm{~km}$, the eastern and the western branches being 75 and $175 \mathrm{~km}$ long, respectively ( $\delta$ is the dip angle, $\phi$ is the average strike of the Motagua fault measured clockwise from north, and $\lambda$ is the slip angle). Sign conventions are given by Kanamori and Stewart [1976a]. The synthetic seismograms for this geometry with a rupture velocity of $3 \mathrm{~km} / \mathrm{s}$ were computed, and the amplitude variation is shown in Figure 3. The fit in the eastern azimuth is significantly improved. We tried a rupture velocity of $2 \mathrm{~km} / \mathrm{s}$; as shown in Figure 3, the asymmetry of the radiation pattern of the synthetic seismogram becomes too large to match the data. However, in view of the scatter of the data a rupture velocity of $2.5 \mathrm{~km} / \mathrm{s}$ is still acceptable. In order to investigate further details of the rupture propagation, the directivity functions were computed for a suite of models and compared with those for several stations. For $G$ waves, three stations, AFI, $\mathrm{AAE}$, and CTA, were chosen because they are nearly in the direction of the fault strike $\left(\phi_{f}=66^{\circ}\right)$ and are most sensitive to the directivity of the source. Since these stations are nearly in the same azimuth $\left(\Theta=8.7^{\circ}\right.$ for $\mathrm{AFI}, 2.7^{\circ}$ for AAE, and $10.2^{\circ}$ for CTA, where $\Theta$ is the angle between the fault strike and the great circle passing through the epicenter and the station), the directivity function was computed for $\Theta=10^{\circ}$. The results are shown in Figure 4. Although the scatter is considerable, it is evident that the combinations $(150,50,2.5)$ and $(175,75,3.0)$ give a satisfactory fit to the data where the first, second, and third numbers in parentheses denote the fault lengths of the western and eastern segments and the rupture velocity, respectively. When a rupture velocity of $2 \mathrm{~km} / \mathrm{s}$ is used, the fit becomes worse than that for these two cases. For Rayleigh waves we chose stations BUL and KIP. These stations are in the direction of the maximum of the radiation pattern, yet they have $\Theta=38.5^{\circ}$ and $40.8^{\circ}$, respectively, and are still sensitive to the source directivity. The directivity functions were computed for $\Theta=41^{\circ}$ and compared with the data in Figure 4. Again the combination $(175,75,3.0)$ gave a satisfactory fit. A rupture velocity of $2 \mathrm{~km} / \mathrm{s}$ did not give a good fit. It is important to note that the dislocation was assumed to be uniform along the fault strike in these models. The fact that these models can explain the observed asymmetric radiation pattern (Figure 3) and the directivities (Figure 4) indicates that the fault displacement, averaged over the length of the fault, is relatively uniform, although small-scale irregularities are very likely to exist. 
As shown in Figure 1, the Motagua fault is not straight but is slightly convex toward the south. For the sake of completeness, synthetic seismograms were computed for the geometry shown at the bottom of Figure 2. In this calculation the fault was broken up into four segments, synthetic seismograms were computed for each segment by the standard method, and then the results for each segment were added with delays appropriate for a rupture velocity of $3 \mathrm{~km} / \mathrm{s}$. The results are shown in Figure 2, and the azimuthal variation of the amplitude is compared with the observed one in Figure 3. The difference between the straight and the curved fault model is very small and is probably unresolvable by the present data. However, it is important that a realistic fault geometry can explain the overall radiation patterns of surface waves and the amplitude ratio of Rayleigh to Love waves very well. By matching the amplitude a seismic moment of $2.6 \times 10^{27} \mathrm{dyn} \mathrm{cm}$ was obtained from both Love and Rayleigh waves.

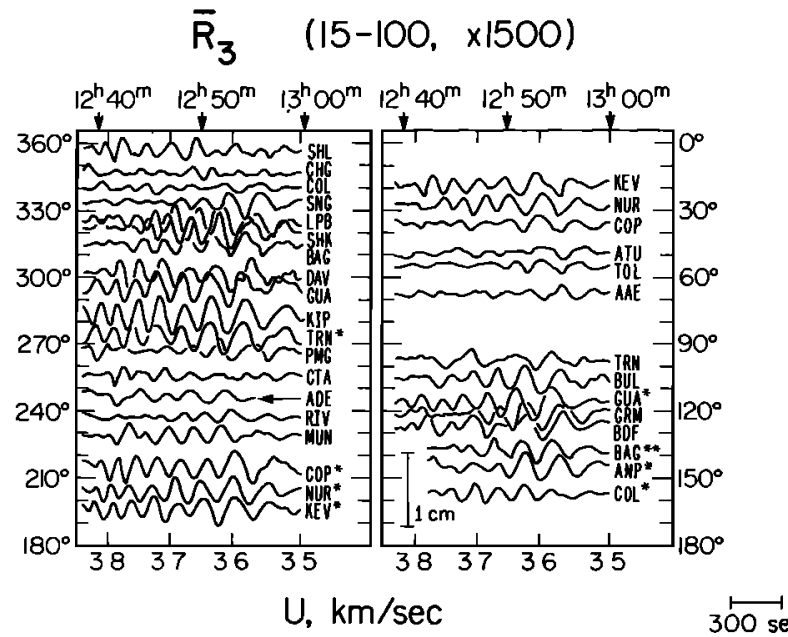

In order to supplement the WWSSN data a seismogram from an ultra-long-period instrument at the Seismological Laboratory, California Institute of Technology, was used. This instrument (PAS, number 33) has a peak response at $150 \mathrm{~s}$ and is adequate for recording very long period surface waves. Figure 5 shows the observed and synthetic $R_{2}$ at Pasadena. No filtering has been applied. The synthetic seismogram was computed for the fault geometry shown at the bottom of Figure 2. The agreement of the wave forms is very good. A seismic moment of $2.3 \times 10^{27} \mathrm{dyn} \mathrm{cm}$ was found which is in good agreement with that obtained from the WWSSN data. This agreement suggests that the source spectrum is flat at periods of $100-300$ s. In the discussion we will use the moment of $2.6 \times 10^{27}$ dyn $\mathrm{cm}$ obtained from the WWSSN data.

The results obtained above can be interpreted in terms of the average dislocation (displacement discontinuity) $\bar{D}$ and the stress drop $\Delta \sigma$. The vertical extent $w$ of the fault cannot be
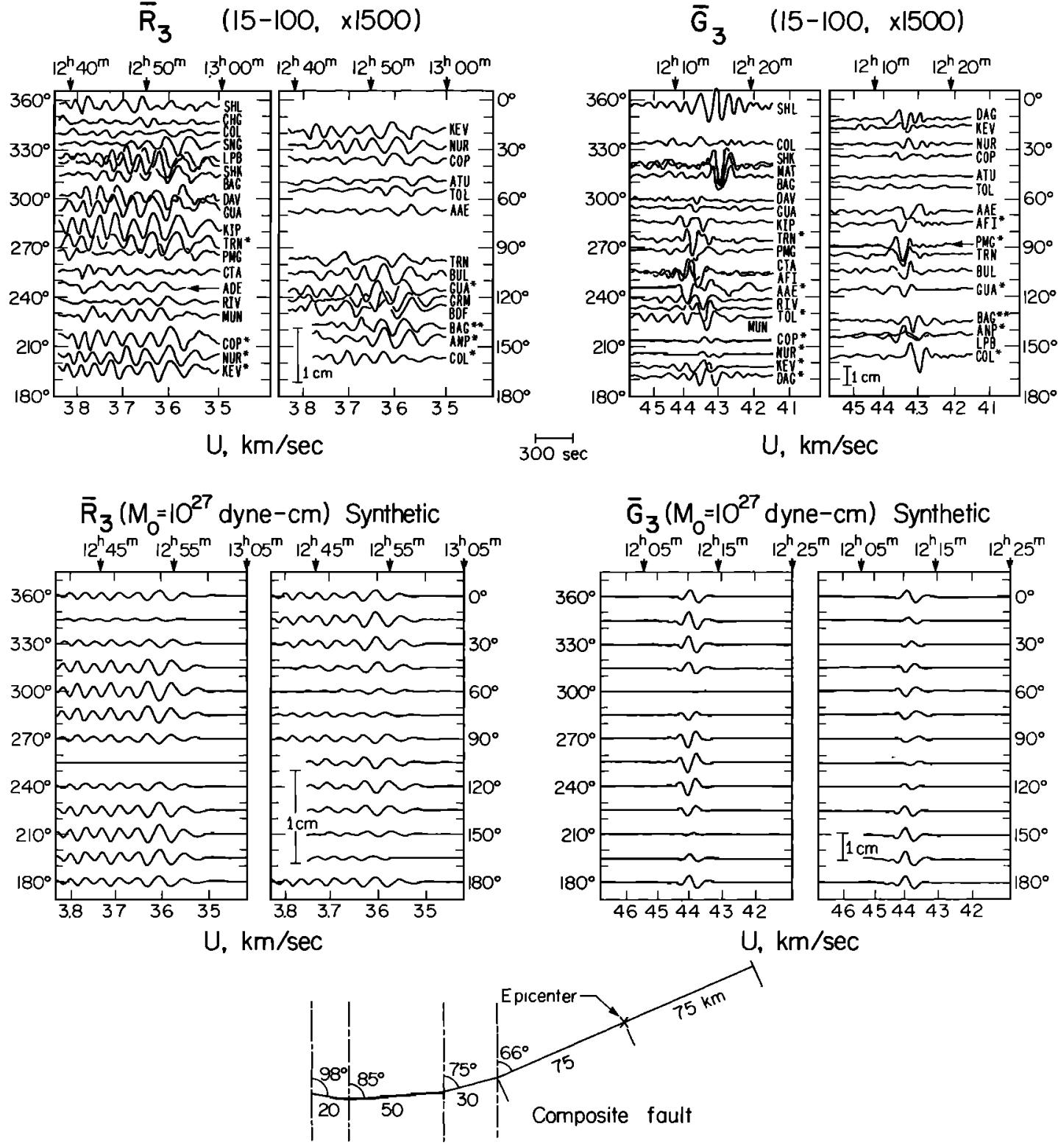

Fig. 2. Azimuthal plots of equalized seismograms for $R_{\mathrm{a}}$ and $G_{\mathrm{a}}$ and synthetic seismograms computed for the composite fault geometry shown. A seismic moment of $10^{27} \mathrm{dyn} \mathrm{cm}$ was used in the synthesis. In the observed patterns, one asterisk indicates that $R_{4}$ and $G_{4}$ data were equalized to $R_{3}$ and $G_{3}$ distances. Two asterisks indicate that $R_{2}$ and $G_{2}$ were equalized to $R_{3}$ and $G_{3}$ distances. The amplitude scale is for the trace amplitude on the WWSSN long-period instrument (15-100) with a magnification of 1500 


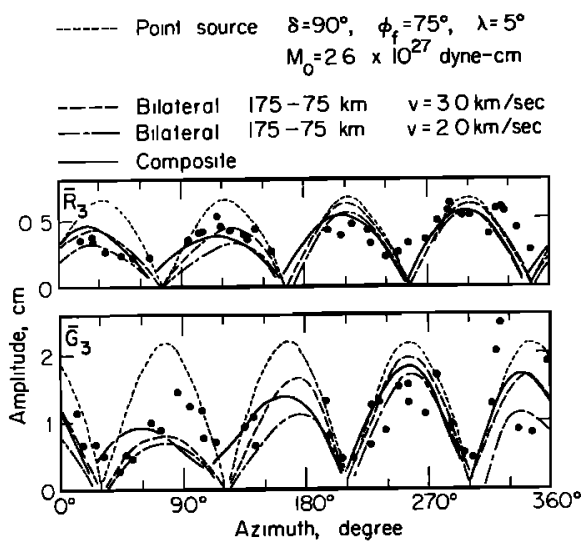

Fig. 3. Equalized station peak-to-peak a mplitudes for observed $R_{\mathrm{B}}$ and $G_{9}$ data plotted as a function of azimuth (solid circles). Curves represent the various fault models used in this study.

directly determined from the present data, but the distribution of the aftershocks indicates that $w \simeq 15 \mathrm{~km}$ (Figure 1). By using the fault length $L=250 \mathrm{~km}$ suggested by the extent of the surface break, the asymmetry, and the directivity we have $\bar{D}=M_{0} / \mu L w=2 \mathrm{~m}$ and $\Delta \sigma=2 \mu \bar{D} / \pi w=30$ bars, where $\mu=$ $3.5 \times 10^{11} \mathrm{dyn} / \mathrm{cm}^{2}$ is used.

Since the wavelength of the surface waves used in the present analysis is longer than about $300 \mathrm{~km}$, these waves are not significantly affected by structural heterogeneity along the propagation path and give a reliable gross average of $\bar{D}$ and $\Delta \sigma$ over the entire length of the fault. Although a depth of 16 $\mathrm{km}$ was used in the above analysis, the amplitude of these long-period surface waves is not sensitive to a change in the source depth from 0 to $16 \mathrm{~km}$, in particular, for a vertical strike slip mechanism.

\section{Body Wave ANalysis}

Although the surface wave analyses described above provide reliable gross fault parameters, they are inadequate to resolve the details of the rupture process. On the other hand, seismic body waves represent the short-period end of the source spec- trum and provide important information regarding the details of the rupture process. Unfortunately, for the Guatemala earthquake, both $P$ and $S$ waves were off scale at most stations. $P$ waves were on scale at some stations near a node of the radiation pattern, but use of these stations for wave form analyses is not desirable. Figure 6 shows wave forms of $P$ waves at seven stations which are considerably removed from the radiation nodes. Except LPB, all stations lie in a narrow azimuthal range from $19.6^{\circ}$ to $41.1^{\circ}$. Thus this data set is somewhat limited in terms of azimuthal coverage, but it is evident that the wave forms at these stations exhibit a very remarkable complexity. Since the distances to these stations are larger than $68^{\circ}$ (except LPB), this complexity is unlikely to be due to later phases. At these distances, the only later phase that arrives within 2 min after the onset of the $P$ wave is the $P c P$ phase, but, for a vertical strike slip fault, $P c P$ is always nearly nodal. Thus most of the complexities are considered to be due to the source. From these figures it appears that the radiation from the source lasted about $2 \mathrm{~min}$. Since the distance to LPB is only $38^{\circ}$ and the $P P$ phase arrives about $1 \mathrm{~min}$ after $P$, only the first minute of that record is shown.

Although the azimuthal coverage of the data is somewhat limited, these records contain extremely important information regarding the rupture process. In the following an attempt is made to interpret these complex records in terms of multiple events. Inspection of these records suggests that at least seven major pulses are distinguishable during the 2-min time interval. Each pulse corresponds to an individual event of the multiple-shock sequence. Since such a sequence involves a very large number of parameters, e.g., source geometry of each event, spatial and temporal separation of the multiple events, strength (the seismic moment), fault length, and rise time of each event, etc., it is extremely difficult to determine all of these parameters. Hence we used the following procedure.

We first took station NUR and tried to match the first part of the $P$ wave record with a synthetic wave form computed for a point source whose time function is adjusted so that it matches the overall wave form of the first pulse of the $P$ wave record. A symmetric trapezoidal source time function with a rise time (and fall-off time) of $4 \mathrm{~s}$ and a total width of $9 \mathrm{~s}$ was chosen (Figure 6). Although the details of this time function

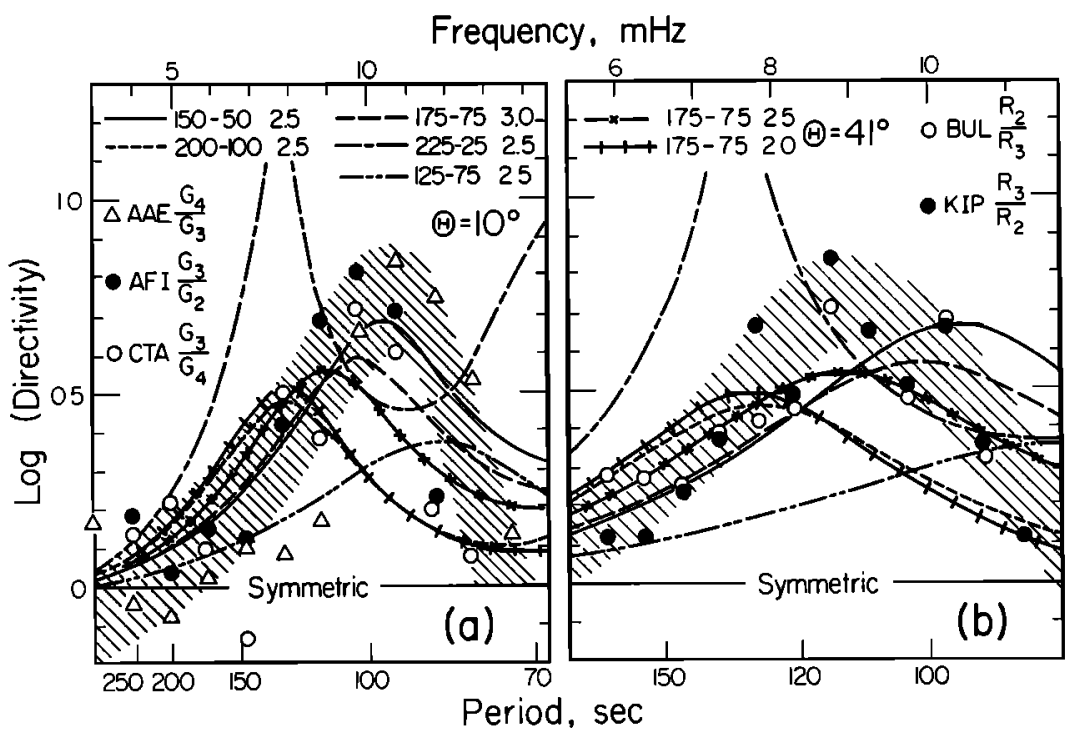

Fig. 4. Observed and computed directivity for (a) Love waves and $(b)$ Rayleigh waves. The preferred model for both data sets is the 175-75-3.0 combination (long-dashed for both sets); $\Theta$ is the angle between the fault strike and the ruplure direction. Hatchings indicate the range of the observed data. 


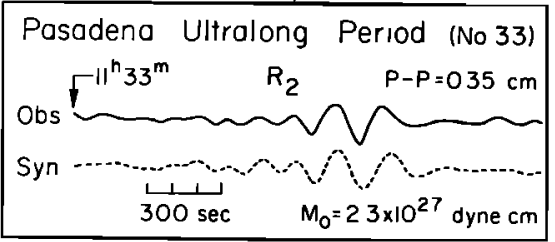

Fig. 5. Observed and synthetic Rayleigh waves $\left(\boldsymbol{R}_{\mathbf{2}}\right)$ at Pasadena (ultra-long-period instrument, number 33 ). Note the agreement of the phase.

are not resolvable by our data, it can explain the first part of the seismogram satisfactorily. The point source was placed at a depth of $5 \mathrm{~km}$ in a homogeneous half space. In the synthesis the surface reflections $p P$ and $s P$ were included (Figure 6). This type of modeling has been successfully applied to the determination of source parameters of relatively simple events [Langston, 1976]. The seismic moment of this first event was estimated to be $1.6 \times 10^{26}$ dyn $\mathrm{cm}$. Then we subtracted the synthetic trace from the observed one and repeated the procedure for the second event. Although the time function and the mechanism of the second event may be different from those of the first event, it is extremely difficult to resolve such details from the available data. We therefore assumed that the time function and the mechanism of the second event are identical to those of the first event. In view of the results of the surface wave analyses, which indicate a relatively uniform left lateral slip over the entire length of the fault, the assumption of the identical mechanism is probably justified even though the fault trace has some degree of curvature. Since the rise time and the pulse width are determined by the initial tectonic stress, stress drop, and dimension of the individual event, they are likely to vary considerably from event to event.

The above procedure was repeated for the later events until the 2 -min record of the $P$ wave was satisfactorily matched. The later events were placed at the same location as the first event. This first approximation to the time sequence of the events was then adjusted to fit the observations better by the method of least squares. Let $S(t)$ and $s(t)$ be the observed $P$ wave and the synthetic wavelet for the individual event ('sum' shown in Figure 6), respectively. We sought to minimize the function

$$
\left[S(t)-\sum_{i=1}^{N} m_{i} s\left(t-t_{t}\right)\right]^{2}
$$

where $m_{i}$ and $t_{i}$ are the moment and the onset time, respectively, of the $i$ th event and $N$ is the total number of events. The

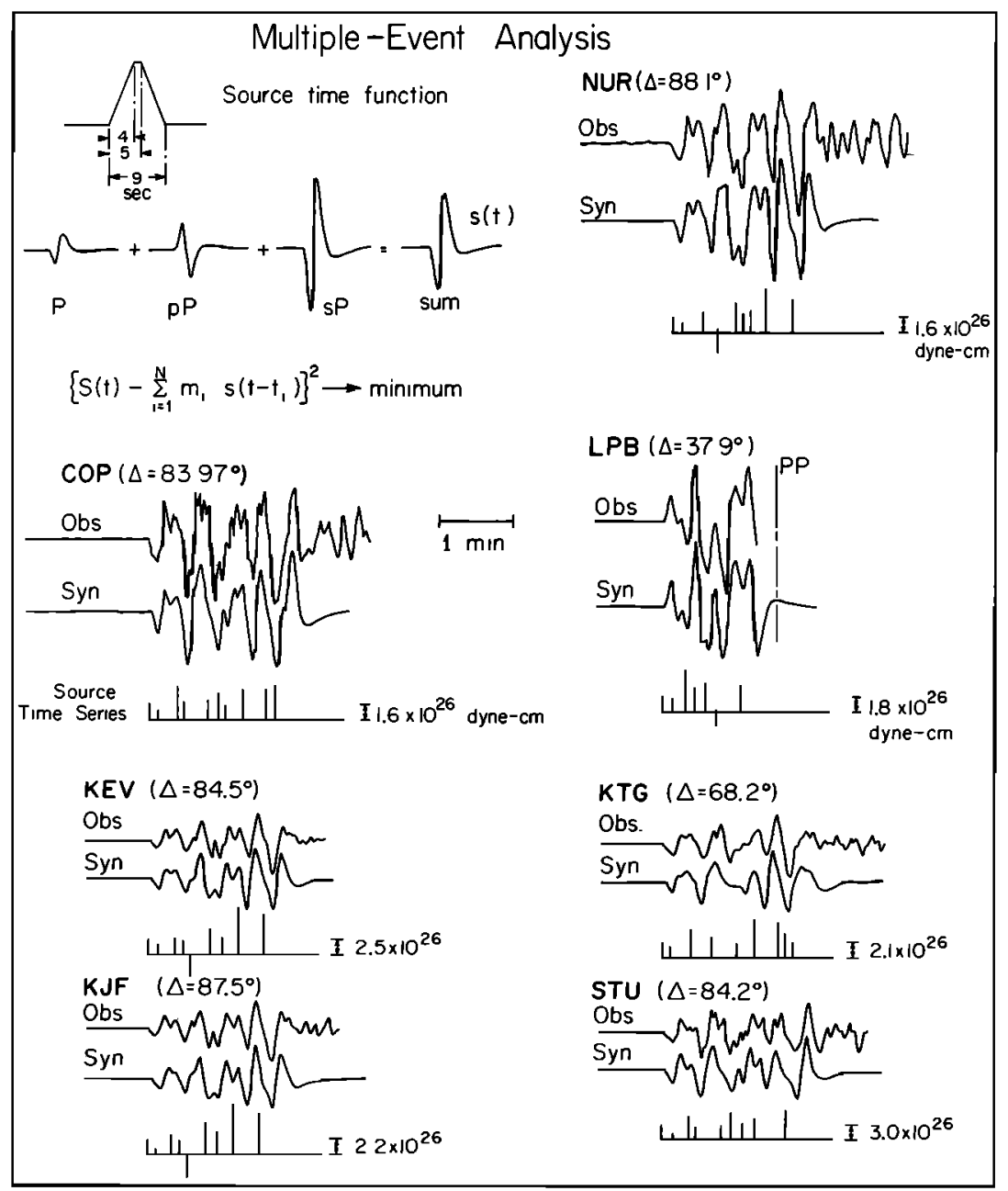

Fig. 6. Observed and synthetic $P$ waves for individual WWSSN stations obtained from the multiple-shock analysis. For each station the source time series is obtained by using the mechanism given in Figure $1 a$ and the source time function shown here. The surface reflections $p P$ and $s P$ are included in the source time function. The resulting series is given for each station along with the moment for the first event. The height of the vertical bar is proportional to the moment of the individual event; $\Delta$ is the epicentral distance. 


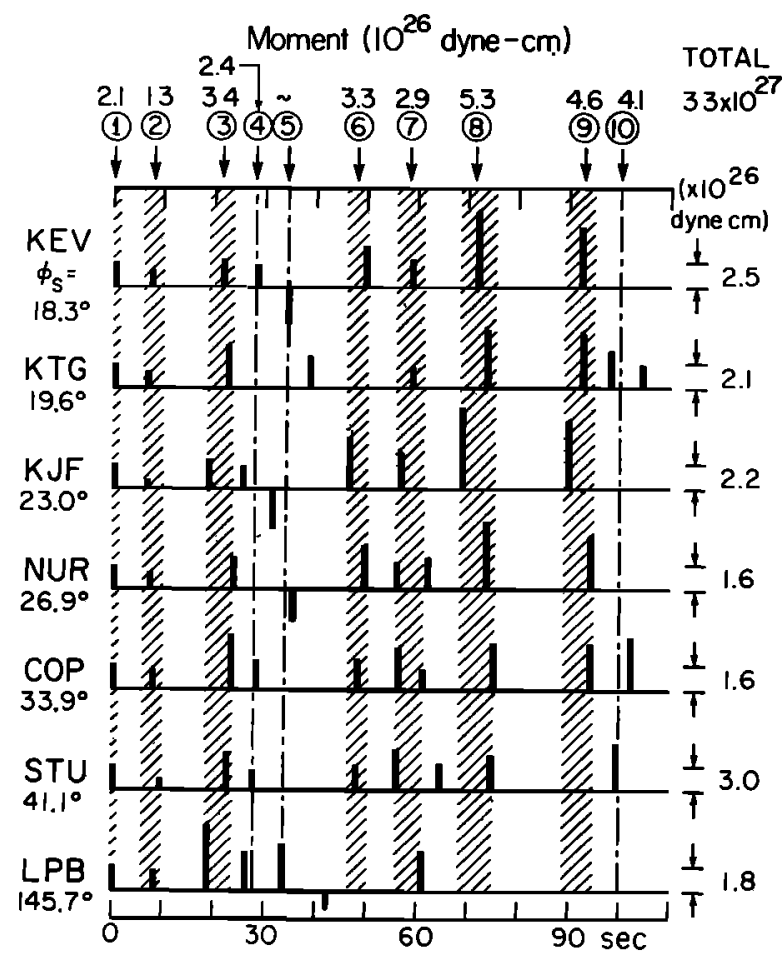

Fig. 7. A comparison of the source time sequences for the seven stations used in this study. The hatched zones denote ranges of arrival times; $\phi_{s}$ is the station azimuth. The values given at the top are the seismic moments of the individual events of the multiple-shock sequence.

result of this inversion is shown in Figure 6. The source time sequences (e.g., plot of $m_{i}$ as a function of $t_{i}$ ) are shown under the individual synthetic records. It is encouraging that a very good match between observed and synthetic records is obtained by a superposition of events having positive $m_{i}$. Only one of the nine events was of reversed polarity. This result suggests that the assumption of identical mechanism is reasonable.

The above method was applied to other signals shown in Figure 6 , and the resulting synthetic records and the source time sequences are shown. In all cases a very good agreement is obtained with a positive $m_{l}$ for most events. If all of the multiple events had the same mechanism and occurred at the same location, the source time sequence should be identical for all the stations. Actually, as shown in Figure 6, the derived source time sequences are similar from station to station, although there are some differences. These irregularities are due to the following causes. First, the various events probably were distributed along the fault, so that the difference between the arrival times of the signals varies from station to station, depending on the azimuth and, to a lesser extent, the distance. Second, noise in the records can cause errors in the measured arrival times of the events. Third, a slight change in the mechanism also results in errors. For a vertical strike slip event all teleseismic $P$ rays leave the source in a nearly nodal direction, so that a slight change in the mechanism can cause a significant change in the wave form, and the determination of the arrival times is thus affected. In view of these complex effects we must allow some ranges of arrival times in identifying the individual events. Figure 7 compares the time sequences for the seven stations. Allowing for ranges of arrival times as shown by hatched belts, we can probably identify events 1,2 , $3,6,7,8$, and 9 as marked on the figure. It may be noted that the eighth and ninth events are 2-2.5 times larger than the first event. A quiet interval of about $10 \mathrm{~s}$ between the second and the third event and a 15-s interval between the eighth and the ninth event are common to all the stations. Some complication is observed around the fourth and fifth events, where some stations indicate a negative pulse. The cause of this complication is unclear, but one possibility is that the arrivals from the eastern and the western branches of the fault interact with each other, resulting in complex wave forms. The average moment of each event is shown at the top of Figure 7. The sum of the moments is $3.3 \times 10^{27} \mathrm{dyn} \mathrm{cm}$, which is slightly larger than that obtained from surface waves. However, in view of the various errors involved in the body wave analysis, this difference is insignificant.

It is interesting to note that Plafker [1976] found very large surface breaks, with a maximum of $3.4 \mathrm{~m}$, near the western end of the fault, about $150 \mathrm{~km}$ to the west of the epicenter (Figure 1). The large events, 8 and 9, probably correspond to these large displacements. If one assumes that the eighth event was $150 \mathrm{~km}$ to the west of the initial epicenter, the time separation of about $72 \mathrm{~s}$ between the first and the eighth event (see Figure 7) suggests an average rupture velocity of about $2 \mathrm{~km} / \mathrm{s}$, which is somewhat smaller than that obtained from the surface wave directivity, viz., $3 \mathrm{~km} / \mathrm{s}$. As is shown in Figure 3, a smooth rupture propagation with a rupture velocity of $2 \mathrm{~km} / \mathrm{s}$ results in a stronger asymmetry than the observed data indicate. However, if the rupture propagation is jagged and partially incoherent as is demonstrated by the $P$ wave analysis, the effect of rupture propagation would become less pronounced than that for smooth propagation [Haskell, 1966]. Thus the value of $3 \mathrm{~km} / \mathrm{s}$ obtained from the surface wave analysis under the assumption of smooth propagation should not be given too much significance. We prefer the result obtained from the $\boldsymbol{P}$ wave analysis: the rupture propagation is jagged with an average velocity of $2 \mathrm{~km} / \mathrm{s}$.

The results of the body wave analysis can be summarized as follows: The entire rupture sequence can be represented by the sequential occurrence of approximately 10 distinct events, the seismic moments of which varied by a factor of about 4 , with time separations varying from 7 to $20 \mathrm{~s}$. Since the average rupture velocity is about $2 \mathrm{~km} / \mathrm{s}$, this variation of time separation corresponds roughly to a spatial separation of 14-40 km. The trapezoidal time function used to model the point sources has an effective pulse width of about $5 \mathrm{~s}$, which corresponds to a source dimension of about $10 \mathrm{~km}$. However, as we mentioned before, the details of the time function cannot be resolved, so that this dimension should be considered a very crude measure of the size of the individual events. It is probable that the source dimensions also varied considerably from event to event.

This complex multiple event may be envisaged in terms of the heterogeneous mechanical properties along the fault plane. This heterogeneity may be caused either by asperities, differences in strength, differences in pore pressure, differences in slip characteristics (stable sliding versus stick slip), or combinations of these factors.

\section{Conclusions AND Discussions}

The seismic moment of the 1976 Guatemala earthquake is estimated from long-period surface waves to be $2.6 \times 10^{27} \mathrm{dyn}$ $\mathrm{cm}$, which suggests an average displacement of $2 \mathrm{~m}$ and a stress drop of 30 bars if the vertical width of the fault is taken as 15 $\mathrm{km}$ on the basis of the aftershock distribution. It is possible that the actual fault plane extends deeper than the aftershock zone, but it is unlikely that a fault plane that is completely incapable of generating aftershocks can generate 100 - to 200-s 
surface waves very efficiently. On this basis we consider that the above estimate, $2 \mathrm{~m}$, of displacement represents the actual average over the depth range of $15 \mathrm{~km}$. On the other hand, Plafker et al. [1976] and Plafker [1976] reported that the average surface displacement measured immediately after the earthquake is about $1 \mathrm{~m}$ with a maximum value of $3.4 \mathrm{~m}$ at one locality. This value is about half the average displacement derived from surface waves. It is possible that the surface layers are partially decoupled from the layers at depth so that the surface displacement represents a fraction of the fault displacement at depth. In this case we might expect postseismic creep along the fault over a prolonged period of time. In fact, Bucknam et al. [1976] and G. Plalker (personal communication, 1977) found a significant increase in the surface offset (as much as $37 \%$ of the initial break) during the period from February to October, 1976. Although the total displacement is still smaller than the seismic displacement, the creep is still continuing, so that it is possible that the surface break will eventually catch up with the displacement at depth. Scholz et al. [1969] suggest that for the 1966 Parkfield earthquake, near-surface afterslip above 4-km depth can explain the discrepancy between surface slip observed immediately after the earthquake and seismic estimates of the average coseismic slip.

On the other hand, we cannot completely exclude the possibility that the fault plane responsible for surface wave radiation is significantly larger than that inferred from the aftershock zone. If this is the case, then both the average displacement and the stress drop would have values lower than those estimated for the vertical width of $15 \mathrm{~km}$ discussed earlier.

The asymmetry of the radiation pattern (Figures 2 and 3) and the directivity (Figure 4) suggest that the displacement is relatively uniform along the entire length of the fault, although short-range irregularities are possible. A rupture velocity of 3 $\mathrm{km} / \mathrm{s}$ is suggested if the displacement is assumed to be uniform.

Teleseismic $P$ waves exhibit a complexity suggesting that this earthquake consists of about 10 distinct events. The duration of the sequence, about $2 \mathrm{~min}$, probably corresponds to the time for the entire fault to break. Analysis of the $P$ wave forms suggests that the fault broke in a relatively coherent manner over distances of only $10 \mathrm{~km}$ or so. The spatial separation of the individual events is $14-40 \mathrm{~km}$, suggesting that either stress, frictional characteristics, or sliding characteristics on the fault plane vary with comparable spatial scale along the fault plane. This result is in striking contrast with that obtained for large earthquakes along the Gibbs fracture zone (transform fault) of the Mid-Atlantic ridge. Kanamori and Stewart [1976a] found that the rupture propagation in these earthquakes is relatively coherent over much longer distances, $40 \mathrm{~km}$ or so. This difference probably reflects the difference in the age of the faults and the structure between the two transform faults and provides an important piece of information regarding the mechanical properties of various types of plate boundaries. Although the average stress drop was relatively low, about 30 bars, the local stress drop for the individual events may have been significantly higher than this, perhaps by a factor of 2 or 3 . Hanks [1974] suggested that the 1971 San Fernando earthquake was characterized by a high stress drop event in the beginning. Burdick and Mellman [1976] reported a relatively high stress drop, 96 bars, over a circular rupture zone of radius $8 \mathrm{~km}$ for the 1968 Borrego Mountain, California, earthquake.

The complexity of the rupture process as revealed by the present analysis has a very important effect on the strong ground motion which results from earthquakes of this type. Haskell [1966] and $A$ ki [1967] showed that irregular fault motion significantly enhances the high-frequency end of the seismic spectrum.

The rate of the instantaneous plate motion of the Caribbean plate with respect to the North American plate in Guatemala is estimated to be about $2 \mathrm{~cm} / \mathrm{yr}$ [Molnar and Sykes, 1969; Jordan, 1975]. Historical records suggest that the repeat time of major earthquakes on the central and western Motagua fault is about 200 years [Spence and Person, 1976]. These results suggest a coseismic displacement of about $4 \mathrm{~m}$ if the strain is released totally in earthquakes. The discrepancy between this value and the average displacement, $2 \mathrm{~m}$, in the 1976 Guatemala earthquake obtained by the present study indicates the following possibilities: (1) half the displacement on the Motagua fault takes place in creep, (2) the repeat time fluctuates considerably, (3) the rate of plate motion has changed, (4) part of the plate motion is taken up by displacements along other faults, and (5) the estimate of the rate of plate motion is in error.

Acknowledgments. We would like to thank the personnel of all the WWSSN stations who were kind enough to send us seismograms. We also thank George Plafker for useful discussions and A. F. Espinosa for an advance copy of U.S. Geological Survey Professional Paper $1002(1976)$. This research was supported by a grant from the National Academy of Sciences, through WDC-A for seismology; the Division of Earth Sciences, by National Science Foundation grant (EAR7614262); and by U.S. Geological Survey contracts 14-08-0001-15893 and 14-08-0001-16776. Contribution 2901, Division of Geological and Planetary Sciences, California Institute of Technology, Pasadena, California 91125.

\section{REFERENCES}

A ki, K., Scaling law of seismic spectrum, J. Geophys. Res., 72, 1217$1231,1967$.

Ben-Menahem, A., Radiation of seismic surface waves from finite moving sources, Bull. Seismol. Soc. Amer., 51, 401-435, 1961.

Bucknam, R. C., G. Plafker, R. V. Sharp, and S. B. Bonis, Surface displacement in the Motagua fault zone during the 4 February 1976 Guatemala earthquake (abstract), Eos Trans. AGU, 57, 949, 1976.

Burdick, L. J., and G. R. Mellman, Inversion of the body waves from the Borrego Mountain earthquake to the source mechanism, Bull. Seismol. Soc. Amer., 66, 1485-1499, 1976.

Dewey, J. W., and B. R. Julian, Main event source parameters from teleseismic data, The Guatemalan Earthquake of February 4, 1976, A Preliminary Report, U.S. Geol. Surv. Prof. Pap., 1002, 19-23, 1976.

Espinosa, A. F. (Ed.), The Guatemalan earthquake of February 4, 1976, A Preliminary Report, U.S. Geol. Surv. Prof. Pap., 1002, 90 pp., 1976.

Hanks, T., The faulting mechanism of the San Fernando earthquake, J. Geophys. Res., 79, 1215-1229, 1974.

Haskell, N., Total energy and energy spectral density of elastic wave radiation from propagating faults, 2, Bull. Seismol. Soc. Amer., 56, $125-140,1966$

Imamura, A., Theoretical and Applied Seismology, 358 pp., Maruzen, Tokyo, 1937.

Jordan, T. H., The present-day motions of the Caribbean plate, $J$. Geophys. Res., 80, 4433-4439, 1975.

Kanamori, H., Synthesis of long-period surface waves and its application to earthquake source studies, Kurile Islands earthquake of October 13, 1963, J. Geophys. Res., 75, 5011-5027, 1970.

Kanamori, H., and J. J. Cipar, Focal process of the great Chilean earthquake May 22, 1960, Phys. Earth Planet. Interiors, 9. 128-136, 1974.

Kanamori, H., and G. S. Stewart, Mode of the strain release along the Gibbs fracture zone, Mid-Atlantic Ridge, Phys. Earth Planet. Interiors, $11,312-332,1976 a$.

Kanamori, H., and G. S. Stewart, The mechanism of the Guatemala earthquake of February 4, 1976, revealed by teleseismic surfacewave and body-wave analysis (abstract), Eos Trans. $A G U, 57,950$, $1976 b$. 
Langer, C. J., J. P. Whitcomb, and A. Aburto Q., Aftershocks from local data, The Guatemalan Earthquake of February 4, 1976, A Preliminary Report, U.S. Geol. Surv. Prof. Pap., 1002, 30-38, 1976.

Langston, C. A., A body wave inversion of the Koyna, India, earthquake of December 10,1967, and some implications for body wave focal mechanisms, J. Geophys. Res., 81, 2517-2529, 1976.

Matumoto, T., and G. V. Latham, Aftershocks of the Guatemalan earthquake of February 4, 1976, Geophys. Res. Lett., 3, 599-602, 1976.

Miyamura, S., S. Omote, R. Teisseyre, and E. Vesanen, Multiple shocks and earthquake series pattern, Int. Inst. Seismol. Earthquake Eng. Bull., 2, 71-92, 1964.

Molnar, P., and L. R. Sykes, Tectonics of the Caribbean and Middle America regions from focal mechanisms and seismicity, Geol. Soc. Amer. Bull., 80, 1639-1684, 1969.

Person, W., W. Spence, and J. W. Dewey, Main event and principal aftershocks from teleseismic data, The Guatemalan Earthquake of February 4, 1976, A Preliminary Report, U.S. Geol. Surv. Prof. Pap., 1002, 17-18, 1976.

Plafker, G., Tectonic aspects of the Guatemala earthquake of 4 February 1976, Science, 93, 1201-1208, 1976.
Plafker, G., M. G. Bonilla, and S. B. Bonis, Geologic effects, The Guatemalan Earthquake of February 4, 1976, A Preliminary Report, U.S. Geol. Surv. Prof. Pap., IO02, 38-51, 1976.

Scholz, C. H., M. Wyss, and S. W. Smith, Seismic and aseismic slip on the San Andreas fault, J. Geophys. Res., 74, 2049-2069, 1969.

Spence, $W$., and $W$. Person, Tectonic setting and seismicity, The Guatemalan Earthquake of February 4, 1976, A Preliminary Report, U.S. Geol. Surv. Prof. Pap., 1002. 4-11, 1976.

Trifunac, M. D., and J. N. Brune, Complexity of energy release during the Imperial Valley, California, earthquake of 1940, Bull. Seismol. Soc. Amer., 60, 137-160, 1970.

Wyss, M., and J. N. Brune, The Alaska earthquake of 28 March 1964: A complex multiple rupture, Bull. Seismol. Soc. Amer., 57, 10171023, 1967.
(Received April 19, 1977; revised November 18, 1977; accepted February 24, 1978.) 